CLINICAL STUDY

\title{
Leptin and adiponectin concentrations in intrauterine growth restricted and appropriate for gestational age fetuses, neonates, and their mothers
}

\author{
Marialena Kyriakakou, Ariadne Malamitsi-Puchner, Helen Militsi ${ }^{1}$, Theodora Boutsikou, Alexandra Margeli ${ }^{1}$, \\ Demetrios Hassiakos, Christina Kanaka-Gantenbein ${ }^{2}$, Ioannis Papassotiriou ${ }^{1}$ and George Mastorakos \\ Neonatal and Endocrine Unit, Second Department of Obstetrics and Gynecology, Athens University Medical School, 10682 Athens, Greece, ${ }^{1}$ Department of \\ Clinical Biochemistry, 'Aghia Sophia' Children's Hospital, Athens, Greece and ${ }^{2}$ First Department of Pediatrics, University Medical School, Athens, Greece
}

(Correspondence should be addressed to G Mastorakos; Email: mastorakg@ath.forthnet.gr)

\begin{abstract}
Objective: Leptin and adiponectin are two adipocytokines that play a critical role in the control of energy balance and metabolism as well as in conditions, such as insulin resistance, inflammation, and the development of the metabolic syndrome in adult life. Leptin has been associated with asymmetric intrauterine growth restriction (IUGR). The aim of this study was to investigate the perinatal implication of leptin and adiponectin in IUGR.

Design: Leptin and adiponectin were measured in the plasma of 40 mothers, in the umbilical cord (UC) blood of their 20 appropriate for gestational age (AGA) and 20 IUGR singleton, full-term fetuses, and neonates on day 1 (d1) and day 4 (d4) of life postnatally.

Methods: Serum leptin and adiponectin levels were measured by RIA. Serum cortisol levels were measured with an electrochemiluminescence immunoassay.

Results: Leptin and adiponectin serum levels were higher and lower respectively in IUGR (mean \pm s.E.M., $32.5 \pm 3.8$ and $5.4 \pm 0.9 \mu \mathrm{g} / \mathrm{l}$ respectively) compared with AGA $(20.4 \pm 2.1$ and $11.8 \pm 1.3 \mu \mathrm{g} / \mathrm{l}$ respectively) mothers $(P<0.05)$, although body mass index did not differ between these two groups. Leptin levels positively correlated with adiponectin levels in the AGA $(r=0.547, P<0.05)$ but not in the IUGR mothers. UC, d1, and d4 leptin and adiponectin levels did not differ between IUGR and AGA groups. UC were significantly higher than d1 leptin levels $(P<0.05)$ in the IUGR group but not in the AGA group. Conclusions: The increased UC leptin levels compared with d1 in IUGR fetuses might be directly and/or indirectly related to the subsequent development of insulin resistance in these neonates. This pathologic situation seems to be related to a specific profile of increased leptin and decreased adiponectin levels in IUGR mothers indicating a genetic predisposition for the development of insulin resistance.
\end{abstract}

European Journal of Endocrinology 158 343-348

\section{Introduction}

Leptin, a 167-amino acid protein, the product of the obese $(\mathrm{ob})$ gene, is mainly produced by adipocytes $(1,2)$. Leptin is a satiety factor that regulates body weight by inducing a decrease in food intake and an increase in energy consumption (3, 4). Plasma leptin concentrations reflect the amount of adipose tissue and they positively correlate with the insulin resistance (5-7). Furthermore, leptin is a pleiotropic hormone and cytokine involved in a number of diverse physiological processes, such as regulation of endocrine functions, inflammation, immune response, reproduction, and angiogenesis $(8,9)$. Adiponectin is a recently described 244-amino acid protein highly expressed in human adipose cells $(10,11)$. It is found in the circulation at varying molecular weight forms resulting from multimerization (12). It modulates insulin action and exerts anti-atherogenic and anti-inflammatory effects (12-14). The adiponectin levels are inversely proportional to body fat content and correlate negatively with the insulin resistance $(12,15,16)$. Altered secretion of both adipocytokines, through their implication in obesity, insulin resistance, and inflammation, may contribute to the development of the metabolic syndrome. Furthermore, adipocytokines (and particularly leptin) have been implicated in intrauterine growth (17).

Intrauterine growth restriction (IUGR) results in significant perinatal and long-term complications, including increased neonatal mortality and morbidity (18) and higher risk for developing metabolic syndrome later in life (19-21). Adverse prenatal environment influences fetal growth and induces thrifty developmental responses in the fetus. These responses may be inappropriate for postnatal environment of nutritional 
excess and they might predispose to disease (22). Animal studies demonstrated that unfriendly environments such as those related to IUGR may lead to permanent regulatory adaptation of the hypothalamicpituitary-adrenal axis (23). In humans, low birth weight is linked to increased fasting cortisol concentrations (24).

To investigate the hypothesis that leptin and adiponectin are implicated in the IUGR condition, we studied these adipocytokines in IUGR fetuses and neonates and their mothers in comparison with appropriate for gestational age (AGA) controls and their mothers.

\section{Subjects and methods}

\section{Subjects}

The Ethics Committee of our teaching hospital approved the study protocol. All included mothers provided signed informed consent before enrollment. Forty pregnant women giving birth consecutively to either 20 AGA or 20 asymmetric IUGR full-term singleton infants with a birth weight below the 3rd customized centile were included in the study. The gestation related optimal weight (GROW) computer-generated program (25) was employed to calculate the customized centile for each pregnancy, taking into consideration significant determinants of birth weight, as maternal height and booking weight, ethnic group, parity, gestational age, and gender (26).

The asymmetric IUGR was associated with preeclampsia, gestational hypertension, and chronic diseases (severe anaemia, type I diabetes mellitus, hepatitis B, and rheumatoid arthritis) in 5, 10, and 5 cases respectively. All IUGR cases were accompanied by small and infarcted placentas of small weight ranging from 255 to $400 \mathrm{~g}$. During the whole duration of pregnancy, 5 mothers reported smoking 10 cigarettes per day. Doppler studies of the uterine and umbilical arteries performed serially in the IUGR group every 10-15 days, starting from the 32nd gestational week, were at the upper physiological limits for gestational age in 13 cases, while in the remaining 7 cases they showed increased impedance to flow. Doppler studies of middle cerebral arteries revealed resistance at the lower physiological limits for gestational age in all IUGR cases, indicating initiation of the blood flow redistribution process. Amniotic fluid as assessed by the largest fluid column on the vertical plane was decreased $(<2 \mathrm{~cm})$ in all IUGR cases.

In the AGA group, mothers were healthy and were either non-smokers or abstained from smoking during pregnancy. Moreover, placentas in the AGA group were normal in appearance and weight. Tests for congenital infections were negative in all women of both groups and neonates showed no symptoms of intrauterine infections or signs of genetic syndromes. In all neonates, 1 - and 5-min Apgar scores were $\geq 8$. Clinical characteristics of participating infants and their mothers are presented in Table 1.

\section{Protocol}

Blood was collected in sterile, pyrogen-free tubes from: i) mothers during the first stage of labor or before receiving anesthesia in cases of elective cesarean section, ii) the doubly clamped umbilical cords (UC) reflecting fetal state, and iii) neonates on post partum day $1(\mathrm{~d} 1)$ and day $4(\mathrm{~d} 4)$, characterizing transition and stabilization to extrauterine life respectively. Blood was immediately centrifuged after clotting and the supernatant serum was kept frozen at $-80^{\circ} \mathrm{C}$ until assay. Ponderal index $\left(\mathrm{PI}=\right.$ weight $(\mathrm{kg}) /$ height $\left.(\mathrm{m})^{3}\right)$, an anthropometric marker employed to define fetal growth, was calculated (27).

\section{Hormone measurements}

Serum leptin levels were measured by employing an RIA kit (Linco Research Inc., St Charles, MO, USA). The minimum detectable concentration, intra- and interassay coefficients of variation were $0.001 \mu \mathrm{g} / \mathrm{l}, 3.6 \%$, and $8.2 \%$ respectively. Serum adiponectin levels were measured by employing an RIA kit (Linco Research Inc). The minimum detectable concentration, intra-, and interassay coefficients of variation were $0.1 \mathrm{mg} / \mathrm{l}, 3.9 \%$, and $8.5 \%$ respectively. Serum cortisol levels were measured by employing an electrochemiluminescence immunoassay (Roche Co). The intra- and interassay coefficients of variation were $1.1-1.3$ and $<8 \%$ respectively.

\section{Statistical analysis}

Leptin, adiponectin, and cortisol values were normally distributed in the studied groups. Wherever needed, unpaired samples $t$-test and ANOVA for repeated measures followed by Fisher's post hoc test were employed. Results were expressed as mean \pm s.E.M. Regression analysis was applied to detect positive

Table 1 Demographic data of appropriate for gestational age (AGA) and intrauterine growth restricted (IUGR) mother/infant pairs expressed as mean \pm S.E.M.

\begin{tabular}{lccc}
\hline & IUGR & AGA & $\boldsymbol{P}$ values \\
\hline Maternal age (years) & $30.8 \pm 6.9$ & $31.2 \pm 4.3$ & $\mathrm{NS}$ \\
Maternal height $(\mathrm{cm})$ & $161 \pm 6$ & $167 \pm 6$ & $<0.05$ \\
Maternal weight $(\mathrm{kg})$ & $59.4 \pm 8.5$ & $60.3 \pm 8.9$ & $\mathrm{NS}$ \\
Maternal BMl (cm/kg) & $22.9 \pm 3.1$ & $21.4 \pm 2.5$ & $\mathrm{NS}$ \\
Gestational age (days) & $265.6 \pm 9.7$ & $272.3 \pm 7.1$ & $<0.05$ \\
Parity (first/other) & $17 / 3$ & $9 / 11$ & $<0.05$ \\
Neonatal weight (kg) & $2.37 \pm 0.26$ & $3.16 \pm 0.26$ & $<0.05$ \\
Male/female fetuses & $7 / 13$ & $8 / 12$ & $\mathrm{NS}$ \\
Mode of delivery & $8 / 12$ & $14 / 6$ & $<0.05$ \\
(VD/ECS) & & & \\
\hline
\end{tabular}

VD, vaginal delivery; ECS, elective cesarean section; NS, non-significant. 
or negative correlations. The level of statistical significance was set at $P<0.05$. Statistical assessment was conducted using STATISTICA 6.0 software package (Tulsa, OK, USA) (28).

\section{Results}

\section{Maternal, fetal, and neonatal hormones levels}

Leptin, adiponectin, and cortisol levels of the mothers of the IUGR and AGA fetuses are reported on Table 2. Leptin (Fig. 1) and adiponectin (Fig. 2) levels were higher and lower respectively in IUGR when compared with AGA mothers $(P<0.05)$. There was no statistically significant difference in leptin and adiponectin levels between smoker and non-smoker IUGR mothers. The ratio of leptin to BMI and that of adiponectin to BMI was higher and lower respectively in IUGR when compared with AGA mothers (leptin to BMI: $1.41 \pm 0.17$ and $0.96 \pm 0.1$ respectively, $P<0.05$; adiponectin to BMI: $0.24 \pm 0.04$ and $0.56 \pm 0.06$ respectively, $P<0.05)$, although maternal BMI did not differ between IUGR and AGA mothers.

Leptin, adiponectin, and cortisol levels in UC, d1, and $\mathrm{d} 4$ are reported on Table 3 . UC, $\mathrm{d} 1$, and $\mathrm{d} 4$ leptin and adiponectin levels did not differ between IUGR and AGA groups. UC leptin levels were significantly higher than $\mathrm{d} 1$ leptin levels $(P<0.05)$ in the IUGR but not in the AGA group, while in both groups they were higher than $\mathrm{d} 4$ leptin levels $(P<0.05)$. No difference was observed between leptin levels of male and female fetuses and neonates. The UC cortisol levels were significantly higher than $\mathrm{d} 4$ cortisol levels $(P<0.05)$ in the IUGR but not in the AGA group. The ratio of cortisol to neonatal body weight was significantly higher in IUGR when compared with AGA in fetuses (UC) only (mean \pm s.e.M., $4.45 \pm 0.93$ vs $2.87 \pm 0.53$, $P<0.05)$ but not in neonates ( $\mathrm{d} 1$ and $\mathrm{d} 4)$.

\section{Correlations among maternal, fetal, and neonatal hormone levels and anthropometric measurements}

In the IUGR group, maternal adiponectin positively correlated with d1 adiponectin levels $(r=0.504$, $P<0.05)$. In the AGA, but not in the IUGR group, maternal leptin positively correlated with maternal

Table 2 Leptin, adiponectin, and cortisol levels in intrauterine growth restricted (IUGR) and appropriate for gestational age (AGA) mothers expressed as mean \pm S.E.M.

\begin{tabular}{lccc}
\hline & Leptin $(\mu \mathrm{g} / \mathrm{l})$ & Adiponectin $(\mathrm{mg} / \mathrm{l})$ & Cortisol $(\mu \mathrm{g} / \mathrm{dl})$ \\
\hline IUGR & $32.5 \pm 3.8$ & $5.4 \pm 0.9$ & $33.3 \pm 3.8$ \\
AGA & $20.4 \pm 2.1$ & $11.8 \pm 1.3$ & $33.8 \pm 2.7$ \\
$P$ values & $<0.05$ & $<0.05$ & $\mathrm{NS}$ \\
\hline
\end{tabular}

NS, non-significant

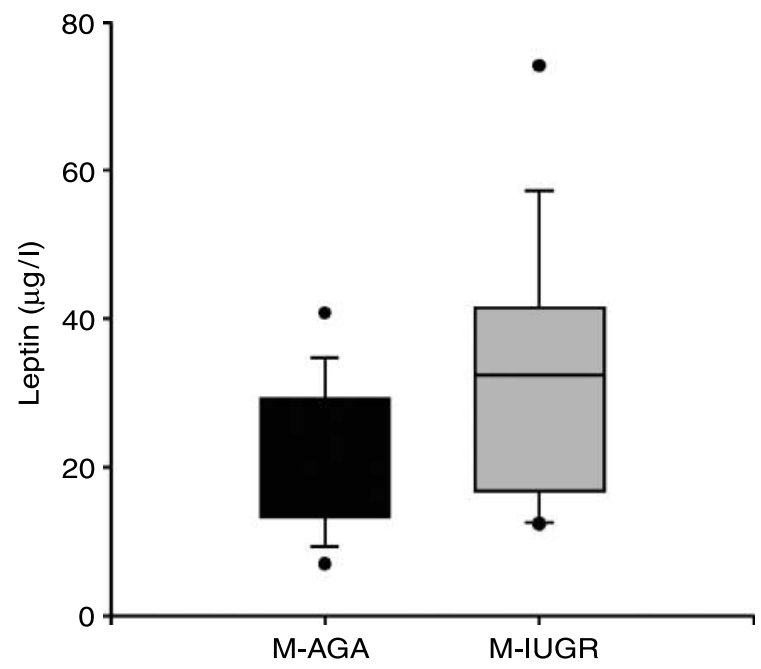

Figure 1 Box and whiskers plot presentation of maternal leptin levels. Each box represents the median concentration with the 5th and 95 th percentile ranges. The upper and lower whiskers represent the range.

adiponectin levels $(r=0.547, P<0.05)$. No correlation was found between maternal and UC leptin and adiponectin levels in any group.

In the IUGR group, UC adiponectin positively correlated with d1 adiponectin levels $(r=0.863$, $P<0.05)$. In the same group, d1 leptin levels positively correlated with PI $(r=0.5, P<0.05)$, whereas $\mathrm{d} 4$ leptin levels positively correlated with gestational age $(r=0.597, P<0.05)$, neonatal weight $(r=0.662$, $P<0.05)$, and length $(r=0.577, P<0.05)$.

In the AGA group, UC leptin positively correlated with d1 $(r=0.749, P<0.05)$ and $\mathrm{d} 4$ leptin $(r=0.784$, $P<0.05)$ levels. In the same group, UC leptin levels

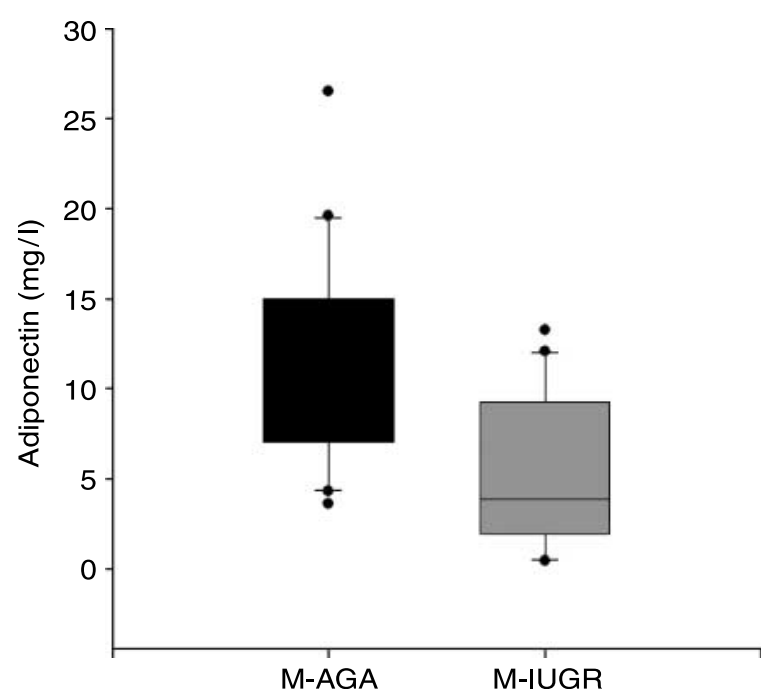

Figure 2 Box and whiskers plots presentation of maternal adiponectin levels. Each box represents the median concentration with the 5th and 95th percentile ranges. The upper and lower whiskers represent the range. 
Table 3 Leptin, adiponectin, and cortisol levels in intrauterine growth restricted (IUGR) and appropriate for gestational age (AGA) umbilical cord (UC), d1, and d4 expressed as mean \pm s.E.M.

\begin{tabular}{lcc}
\hline & IUGR & AGA \\
\hline Leptin-UC $(\mu \mathrm{g} / \mathrm{l})$ & $12.5 \pm 5.3^{\star}, \dagger$ & $9.6 \pm 1.9^{\dagger}$ \\
Leptin-d1 $(\mu \mathrm{g} / \mathrm{l})$ & $1.7 \pm 0.2$ & $3.6 \pm 0.9$ \\
Leptin-d4 $(\mu \mathrm{g} / \mathrm{l})$ & $2.0 \pm 0.2$ & $2.7 \pm 0.3$ \\
Adiponectin-UC $(\mathrm{mg} / \mathrm{l})$ & $19.9 \pm 3.1$ & $27.3 \pm 2.1$ \\
Adiponectin-d1 $(\mathrm{mg} / \mathrm{l})$ & $17.0 \pm 3.4$ & $26.0 \pm 2.2$ \\
Adiponectin-d4 $(\mathrm{mg} / \mathrm{l})$ & $20.4 \pm 2.6$ & $22.8 \pm 2.2$ \\
Cortisol-UC $(\mu \mathrm{g} / \mathrm{dl})$ & $10.6 \pm 2.2^{\dagger}$ & $9.1 \pm 1.6$ \\
Cortisol-d1 $(\mu \mathrm{g} / \mathrm{dl})$ & $8.6 \pm 1.6$ & $7.0 \pm 1.4$ \\
Cortisol-d4 $(\mu \mathrm{g} / \mathrm{dl})$ & $7.1 \pm 1.0$ & $5.5 \pm 0.9$ \\
\hline
\end{tabular}

*Indicates statistically significant difference within the same group (either IUGR or AGA) between UC and d1 values at the level of $P<0.05$. 'Indicates statistically significant difference within the same group (either IUGR or AGA) between UC and d4 values at the level of $P<0.05$.

positively correlated with gestational age $(r=0.619$, $P<0.05)$, d1 leptin levels positively correlated with neonatal weight $(r=0.447, P<0.05)$, and PI $(r=0.552, P<0.05)$ and $\mathrm{d} 4$ leptin levels positively correlated with gestational age $(r=0.729, P<0.05)$.

\section{Discussion}

We found that neonatal $(\mathrm{d} 4)$ leptin levels were lower than fetal (UC) ones in both IUGR and AGA groups. It has been reported that in AGA and small for gestational age (SGA) infants, fetal leptin levels decreased within the first post partum days, regardless of birth body weight $(29,30)$. Leptin levels reflect the amount of adipose tissue (29) and during pregnancy, fetal leptin levels increase in parallel with its development $(32,33)$. The decrease of leptin levels during the first days of life might reflect the transitory loss of weight during that period of life (31). Leptin is involved in the regulation of body weight through a feedback loop between adipose tissue and the satiety center, resulting in decreased food intake and increased energy expenditure (31). Thus, the post partum leptin decrease limits neonatal body energy expenditure by conserving the nutritional reserves for growth and development (34), while it stimulates feeding behavior (35). Although leptin has been shown to have proinflammatory properties (36), the increased levels of this adipocytokine in the UC compared with $\mathrm{d} 1$ and $\mathrm{d} 4$ levels cannot be attributed to inflammation because the studied neonates, and presumably the fetuses, presented no sign of inflammation. No difference was observed between leptin levels of male and female fetuses and neonates of either studied group. In the past, certain studies have suggested that leptin levels are higher in female fetuses, while others did not confirm this finding $(29,32,37$, 38). Further studies with increased number of cases might be useful to clarify whether the known gender dimorphism in leptin levels found later in life might exist during intrauterine and neonatal life $(39,40)$.
In this study, leptin levels did not differ between IUGR and AGA fetuses or neonates. In the past, Harigaya et al. reported no significant differences in leptin levels among AGA, SGA, and large for gestational age infants after $48 \mathrm{~h}$ of life (29), while certain studies reported lower leptin levels in SGA than in AGA infants $(38,41,42)$. In these studies, the authors examined SGA rather than IUGR infants, while in our study IUGR infants had a birth weight below the 3rd customized centile as calculated by the GROW computer-generated program (25). This selection bias might result in the discrepancies observed in leptin levels. Percent body fat is reduced in IUGR when compared with AGA neonates, while intra-abdominal adipose tissue is not reduced in the former when compared with the latter (43). It is possible that the lack of difference in leptin levels between IUGR and AGA in this study might reflect a more active leptin production from intra-abdominal adipose tissue in IUGR than in AGA fetuses. Intraabdominal adipose tissue, as well as leptin, is implicated in the development of insulin resistance. The latter has been linked to IUGR pathophysiology $(44,45)$. In a recent study of 6 - to 8-year-old SGA and AGA children, the former were more insulin resistant than the latter (46). In another study, metabolic syndrome was observed in $2.3 \%$ of adults born SGA versus $4 \%$ of adults born AGA (47). In the AGA group, fetal leptin levels correlate with neonatal $\mathrm{d} 1$ and $\mathrm{d} 4$ leptin levels. This does not happen in the IUGR group, probably because the fall of leptin levels between UC and $\mathrm{d} 4$ is more pronounced than that in the AGA group. Eventually, this is due to the post partum disappearance of the intrauterine stress factor that is presumably responsible for the IUGR state. Indeed, the ratio of UC cortisol to birth weight is higher in IUGR than AGA neonates, while in extrauterine life ( $\mathrm{d} 1$ and $\mathrm{d} 4$ ) this ratio does not differ between them. Cortisol levels should be considered as a reliable stress index.

In the present study, in the IUGR group, neonatal $\mathrm{d} 4$ leptin levels correlated with gestational age, while in the AGA group both fetal and neonatal d4 leptin levels correlated with gestational age. These correlations reflect the increase of adipose tissue along with the gestational progress, particularly during late gestation in AGA (48), and possibly a post partum catch-up in IUGR group. In the past, in AGA, a positive correlation has been shown between fetal leptin levels and gestational age $(49,50)$. Thus, it seems that maturity, as indicated by gestational age, is a significant determinant of leptin levels in fetuses and neonates, also according to previous studies performed in preterm and term infants $(29,32,51)$.

Adiponectin levels did not differ from fetal to neonatal d1 and $\mathrm{d} 4$ in IUGR and AGA groups, as well as between these two groups in all time points studied. Similarly, Martinez et al. did not find any difference in adiponectin levels between SGA and AGA infants (38) and Kotani et al. did not find different adiponectin levels 
in neonates (postnatal day 3-7) compared with those in cord blood (52).

In our study, maternal adiponectin and leptin levels were lower and higher respectively in IUGR compared with AGA mothers. This finding might reflect the state of inflammation and chronic stress in IUGR mothers, eventually predisposing them to the development of insulin resistance. Mise et al. postulate that elevated maternal plasma leptin concentration in preeclampsia is caused mostly by the augmentation of placental production of leptin in response to hypoxia (53). Reduced uteroplacental blood flow, leading to fetoplacental hypoxia, is important in the pathogenesis of IUGR (54). On the other hand, maternal leptin levels positively correlated with maternal adiponectin levels in the AGA but not in the IUGR group, possibly indicating the crucial role of leptin for the development of insulin resistance in the mothers of IUGR. Thus, it seems that these two adipocytokines are interrelated in AGA but not in IUGR mothers. Given the antiinflammatory role of adiponectin (55), in contrast to the pro-inflammatory role of leptin (36), this correlation may reflect a compensatory mechanism to counteract directly and/or indirectly the inflammatory state of parturition, which is functional in AGA but not in IUGR cases. The higher leptin-to-BMI and the lower adiponectin-to-BMI ratios in IUGR when compared with AGA mothers, although their BMI did not differ, might imply that there is a predisposition of the IUGR mothers' adipocytes to produce more leptin and less adiponectin. Therefore, it is possible that IUGR fetuses bear a genetic predisposition to increased leptin and decreased adiponectin production.

We conclude that the relatively increased leptin levels in IUGR fetuses compared with d1 IUGR neonates might be directly and/or indirectly related to later development of insulin resistance. This pathologic situation seems to be related to a specific maternal profile of increased leptin and decreased adiponectin levels in IUGR mothers indicating a genetic predisposition for the development of insulin resistance. Because increased percent adipose tissue correlates well with insulin resistance and preeclampsia, it would be useful to propose to pregnant IUGR mothers to pay attention to their weight because this could be detrimental for them and their offspring.

\section{References}

1 Zhang Y, Proenca R, Maffei M, Barone M, Leopold L \& Friedman JM. Positional cloning of the mouse obese gene and its human homologue. Nature $1994372425-432$.

2 Ahima RS \& Flier JS. Leptin. Annual Review of Physiology 200062 413-437.

3 Ahima RS, Prabakaran D, Mantzoros C, Ou D, Lowell B, MaratosFlier E \& Flier JS. Role of leptin in the neuroendocrine response to fasting. Nature $1996 \mathbf{3 8 2} 250-252$.
4 Chan JL, Heist K, DePaoli AM, Veldhuis JD \& Mantzoros CS. The role of falling leptin levels in the neuroendocrine and metabolic adaptation to short term starvation in healthy men. Journal of Clinical Investigation 2003111 1409-1421.

5 Zimmet P, Hodge A, Nicolson M, Staten M, de Courten M, Moore J, Morawiecki A, Lubina J, Collier G, Alberti G \& Dowse G. Serum leptin concentration, obesity and insulin resistance in Western Samoans: cross sectional study. BMJ 1996313 965-969.

6 de Courten M, Zimmet P, Hodge A, Collins V, Nicolson M, Staten M, Dowse G \& Alberti KG. Hyperleptinaemia: the missing link in the metabolic syndrome. Diabetic Medicine 199714 200-208.

7 Valle MŸ, Gascon F, Martos R, Bermudo F, Ceballos P \& Suanes A. Relationship between high plasma leptin concentrations and metabolic syndrome in obese pre-pubertal children. International Journal of Obesity and Related Metabolic Disorders 200327 13-18.

8 Otero M, Lago R, Lago F, Casanueva FF, Diequez C, Gomez-Reino JJ \& Gualillo O. Leptin from fat to inflammation: old questions and new insights. FEBS Letters 2005 579 295-301.

9 Lappas M, Permezel M \& Rice GE. Leptin and adiponectin stimulate the release of proinflammatory cytokines and prostaglandins from human placenta and maternal adipose tissue via nuclear factorkappaB, peroxisomal proliferator-activated receptor-gamma and extracellularly regulated kinase 1/2. Endocrinology 2005146 3334-3342.

10 Maeda K, Okubo K, Shimomura I, Funahashi T, Matsuzawa Y \& Matsubara K. cDNA cloning and expression of a novel adipose specific collagen-like factor, apM1. Biochemical and Biophysical Research Communications 1996221 286-289.

11 Scherer PE, Williams S, Fogliano M, Baldini G \& Lodish HF. A novel serum protein similar to C1q, produced exclusively in adipocytes. Journal of Biological Chemistry 1995 270 26746-26749.

12 Whitehead JP, Richards AA, Hickman IJ, Macdonald GA \& Prins JB. Adiponectin - a key adipokine in the metabolic syndrome. Diabetes, Obesity and Metabolism 20068 264-280.

13 Yildiz BO, Suchard MA, Wong ML, McCann SM \& Licinio J. Alterations in the dynamics of circulating ghrelin, adiponectin, and leptin in human obesity. PNAS 2004101 10434-10439.

14 Diez JJ \& Iglesisas P. The role of the novel adipocyte-derived hormone adiponectin in human disease. European Journal of Endocrinology 2003148 293-300.

15 Weyer C, Funahashi T, Tanaka S, Hotta K, Matsuzawa Y, Pratley RE \& Tataranni PA. Hypoadiponectinemia in obesity and type 2 diabetes: close association with insulin resistance and hyperinsulinemia. Journal of Clinical Endocrinology and Metabolism 200186 1930-1935.

16 Matsubara M, Maruoka S \& Katayose S. Inverse relationship between plasma adiponectin and leptin concentrations in normalweight and obese women. European Journal of Endocrinology 2002 147 173-180.

17 Mostyn A, Keisler DH, Webb R, Stephenson T \& Symonds MF. The role of leptin in the transition from fetus to neonate. Proceedings of the Nutrition Society 200160 187-194.

18 Gluckman PD \& Harding JE. Fetal growth retardation: underlying endocrine mechanisms and postnatal consequences. Acta Paediatrica. Supplement $1997 \mathbf{4 2 2} 69-72$.

19 Barker DJ, Hales CN, Fall CH, Osmond C, Phipps K \& Clark PM. Type 2 (non-insulin-dependent) diabetes mellitus, hypertension and hyperlipidaemia (syndrome $\mathrm{X}$ ): relation to reduced fetal growth. Diabetologia $19933662-67$.

20 Eriksson JG, Forsen T, Tuomilehto J, Jaddoe VW, Osmond C \& Barker DJ. Effects of size at birth and childhood growth on the insulin resistance syndrome in elderly individuals. Diabetologia $200245342-348$.

21 Valdez R, Athens MA, Thompson GH, Bradshaw BS \& Stern MP. Birthweight and adult health outcomes in a biethnic population in the USA. Diabetologia 199437 624-631.

22 Bateson P, Barker DJP, Clutton-Brock T, Deb D, D’Udine B, Foley RA, Gluckman PD, Godfrey KM, Kirkwood T, Lahr MM, McNamara J, Metcalfe NB, Monaghan P, Spencer HG \& Sultan SE. Developmental plasticity and human health. Nature $2004 \mathbf{4 3 0}$ 419-421. 
23 Wingfield JC, Maney DL, Breuner CW, Jacobs JD, Lynn S, Ramenofsky M \& Richardson RD. Ecological bases of hormonebehavior interactions: the 'emergency life history stage'. American Zoologist 199838 191-206.

24 Phillips DIW, Barker DJP, Fall CHD, Seckl JR, Whorwood CB, Wood PJ \& Walker BR. Elevated plasma cortisol concentrations: a link between low birth weight and the insulin resistance syndrome? Journal of Clinical Endocrinology and Metabolism 1998 83 757-760.

25 Gardosi J, Chang A, Kaylan B, Sahota D \& Symonds EM. Customised antenatal growth charts. Lancet 1992339 283-287.

26 Gardosi J, Mongelli M, Wilcox M \& Chang A. An adjustable fetal weight standard. Ultrasound Obstetrics and Gynecology 19956 168-174.

27 Roje D, Ivo B, Ivica T, Mirjana V, Vesna C, Aljosa B, Marko V, Zoran M, Marko M \& Tomislav M. Gestational age - the most important factor of neonatal ponderal index. Yonsei Medical Journal 200445 273-280.

28 Statsoft, Inc. STATISTICA version 6, www.statsoft.com, 2001.

29 Harigaya A, Nagashima K, Nako Y \& Morikawa A. Relationship between concentration of serum leptin and fetal growth. Journal of Clinical Endocrinology and Metabolism $1997103281-3284$.

30 Sarandakou A, Protonotariou E, Rizos D, Malamitsi-Puchner A, Giannaki G, Phocas I \& Creatsas G. Serum leptin concentrations during the perinatal period. American Journal of Perinatology 2000 17 325-328.

31 Park MJ, Namgung R, Kim JN \& Kim DH. Serum leptin, IGF-1 and insulin in preterm infants receiving parenteral nutrition during the first week of life. Journal of Pediatric Endocrinology and Metabolism 200114 429-433.

32 Jaquet D, Leger J, Levy-Marchal C, Oury JF \& Czenichow P. Ontogeny of leptin in human fetuses and newborns: effect of intrauterine growth retardation on serum leptin concentrations. Journal of Clinical Endocrinology and Metabolism 199883 1243-1246.

33 Gomez L, Carrascosa A, Yeste D, Potau N, Rique S, Ruiz-Cuevas P \& Almar J. Leptin values in placental cord blood of human newborns with normal intrauterine growth after 30-42 weeks of gestation. Hormone Research 199951 10-14.

34 Ng PC, Lam CW, Lee CH, Wong GW, Fok TF, Chan IH, Ma KC \& Wong E. Leptin and metabolic hormones in preterm newborns. Archives of Disease in Childhood. Fetal and Neonatal Edition 2000 83 198-202.

35 Schubring C, Siebler T, Kratzsch J, Englaro P, Blum WF, Triep K \& Kiess W. Leptin serum concentrations in healthy neonates within the first week of life: relation to insulin and growth hormone levels, skinfold thickness, body mass index and weight. Clinical Endocrinology 199951 199-204.

36 Hasenkrug KJ. The leptin connection: regulatory $\mathrm{T}$ cells and autoimmunity. Immunity 200726 143-145.

37 Petridou E, Mantzoros CS, Belechri M, Skalkidou A, Dessypris N, Papathoma E, Salvanos H, Lee JH, Kedikoglou S, Chrousos G \& Trichopoulos D. Neonatal leptin levels are strongly associated with female gender, birth length, IGF-1 levels and formula feeding. Clinical Endocrinology 200562 366-371.

38 Martinez-Cordero C, Amador-Licona NA, Guizar-Mendoza JM, Hernandez-Mendez J \& Ruelas-Orozco G. Body fat at birth and cord blood levels of insulin, adiponectin, leptin and insulin-like growth factor 1 in small for gestational age infants. Archives of Medical Research 200637 490-494.

39 Ghizzoni L \& Mastorakos G. Interactions of leptin, GH, and cortisol in normal children. Annals of the New York Academy of Sciences $200399756-63$.
40 Mastorakos G \& Zapanti E. The hypothalamic-pituitary-adrenal axis in the neuroendocrine regulation of food intake and obesity: the role of corticotropin releasing hormone. Nutritional Neuroscience $20047271-280$.

41 Pighetti M, Tommaselli GA, D’Elia A, Di Carlo C, Mariano A, Di Carlo A \& Nappi C. Maternal serum and umbilical cord blood leptin concentrations with fetal growth restriction. Obstetrics and Gynecology 2003102 535-543.

42 Catov JM, Patrick TE, Powers RW, Ness RB, Harger G \& Roberts JM. Maternal leptin across pregnancy in women with small-forgestational-age infants. American Journal of Obstetrics and Gynecology $2007196558 \mathrm{e} 1-558 \mathrm{e} 8$.

43 Harrington TA, Thomas EL, Frost G, Modi N \& Bell JD. Distribution of adipose tissue in the newborn. Pediatric Research 200455 437-441.

44 Veening MA, Van Weissenbruch MM \& Delemarre-Van De Waal HA. Glucose tolerance, insulin sensitivity, and insulin secretion in children born small for gestational age. Journal of Clinical Endocrinology and Metabolism 200287 4657-4661.

45 Li C, Johnson MS \& Goran MI. Effects of low birth weight on insulin resistance syndrome in Caucasian and African-American children. Diabetes Care 200124 2035-2042.

46 Evangelidou EN, Giapros VI, Challa AS, Kiortsis DN, Tsatsoulis AA \& Andronikou SK. Serum adiponectin levels inslin resistance, and lipid profile in children born small for gestational age are affected by the severity of growth retardation at birth. European Journal of Endocrinology $2007156271-277$.

47 Jaquet D, Deghmoun S, Chevenne D, Collin D, Chernichow P \& Levy-Marchal C. Dynamic change in adiposity from fetal to postnatal life is involved in the metabolic syndrome associated with reduced fetal growth. Diabetologia $2005 \mathbf{4 8} 849-855$.

48 Carrera JM, Devesa R \& Carrera M. Dynamics of fetal growth. In Textbook of Perinatal Medicine, pp 1140-1147. Ed. A Kurjak, London: The Parthenon Publishing Group, 1998.

49 Ogueh O, Sooranna S, Nicolaides KH \& Johnson MR. The relationship between leptin concentration and bone metabolism in the human fetus. Journal of Clinical Endocrinology and Metabolism 200085 1997-1999.

50 Pardo IM, Geloneze B, Tambascia MA \& Barros-Filho AA. Does maternal smoking influence leptin levels in term, appropriate-forgestational-age newborns? Journal of Maternal-Fetal and Neonatal Medicine 200415 408-410.

51 Shekhawat PS, Garland JS, Shivpuri C, Mick GJ, Sasidharan P, Pelz CJ \& McCormick KL. Neonatal cord blood leptin: its relationship to birthweight, body mass index, maternal diabetes and steroids. Pediatric Research 199843 338-343.

52 Kotani Y, Yokota I, Kitamura S, Matsuda J, Naito E \& Kuroda Y. Plasma adiponectin levels in newborns are higher than those in adults and positively correlated with birth weight. Clinical Endocrinology 200461 416-417.

53 Mise H, Sagawa N, Matsumoto T, Tura S, Nanno H, Itoh H, Mori T, Masuzaki H, Hosoda K, Ogawa Y \& Nakao K. Augmented placental production of leptin in preeclampsia: possible involvement of placental hypoxia. Journal of Clinical Endocrinology and Metabolism 199883 3225-3229.

54 Redman CWG. Current topic: preeclampsia and the placenta. Placenta 199112 301-308.

55 Ouchi N \& Walsh K. Adiponectin as an anti-inflammatory factor. Clinica Chimica Acta $2007 \mathbf{3 8 0} 24-30$.

Received 30 November 2007

Accepted 3 December 2007 